\title{
The Influence of Hormones on the Biochemical Development of Fetal Rat Lung in Organ Culture. II. Insulin
}

\author{
IAN GROSS. ${ }^{2 \% \prime}$ G. J. WALKER SMITH, CHRISTINE M. WILSON. WILLIAM M. MANISCALCO. \\ LINDA D. INGLESON, ARLETTE BREHIER, and SEAMUS A. ROONEY \\ Division of Perinatal Medicine. Departments of Pediatrics. Ohstetrics and Ginecologiv and Pathologl. Yale University. \\ School of Medicine. New Haven. Connecticut. USA
}

\begin{abstract}
Summary
The influence of insulin on the biochemical and morphologic maturation of 19-day fetal rat lung (term is 22 days) was studied in an organ culture system. Exposure to insulin for $24 \mathrm{hr}$ resulted in a significant increase in the glycogen content and the rate of glucose oxidation to $\mathrm{CO}_{2}$. In association with this, there was morphologic evidence of delayed lung maturation as evidenced by a significant decrease in the number of lamellar bodies and type II cells in the explants.

Insulin treatment had no effect on the rate of choline incorporation into phosphatidylcholine (PC) or disaturated $\mathrm{PC}$ and did not antagonize the dexamethasone-induced stimulation of choline incorporation into $\mathrm{PC}$. When the incorporation of $\left.\right|^{3} \mathrm{H} \mid$ acetate into the various phospholipid fractions was examined, however, it was found that exposure to insulin resulted in a significant decrease in the percentage of phospholipid radioactivity in the disaturated PC fraction and an increase in the percentage of radioactivity in the "membrane" phospholipids, phosphatidylethanolamine, phosphatidylinositol plus phosphatidylserine, and sphingomyelin. There was no significant change in the unsaturated $P C$ and phosphatidylglycerol fractions. Treatment with dexamethasone generally had the opposite effect to insulin with regard to acetate incorporation into the various phospholipid fractions, and when the two hormones were combined, this effect was diminished or abolished. The effects of insulin could not be accounted for on the basis of a change in activity of any of the enzymes of phospholipid synthesis that were examined.

These findings suggest that insulin stimulates the synthesis of the cell membrane phospholipids while decreasing that of the surfactant phospholipid, disaturated PC.
\end{abstract}

\section{Speculation}

Insulin stimulates lung cell growth while delaying lung cell differentiation.

The fetus in a diabetic pregnancy is exposed to high levels of endogenous insulin because glucose crosses the placenta freely from the hyperglycemic mother and stimulates insulin production by the fetal pancreas $(13,14)$. Maternal insulin does not cross to the fetus. A possible role for insulin in the regulation of fetal lung maturation was suggested by the study of Robert et al. (18) which found that infants born to diabetic mothers had an increased susceptibility to the respiratory distress syndrome (RDS) of the newborn. These investigators reported that the increased incidence of RDS was not due merely to the fact that these infants tend to be born prematurely or by caesarian section.

Smith et al. (25) then reported that insulin abolished the cortisolinduced stimulation of choline incorporation into phosphatidylcholine $(P C)$ in mixed fetal rabbit lung cell cultures. PC is an important component of pulmonary surfactant, and the disatur- ated species of this phospholipid is believed to play a major role in lowering surface tension at the air-alveolar interface, thereby preventing atelectasis of the lungs. Subsequent in vivo studies have, however, produced conflicting results regarding the influences of insulin on lung phospholipid synthesis. Sosenko et al. (26) and Rhoades (17), working with the offspring of glucose intolerant rabbits and rats, have presented data suggesting that lung maturation is delayed in these animals, whereas Epstein $e t$ al. (4) found no decrease in the rate of choline incorporation into $\mathrm{PC}$ in the lungs of the fetuses of glucose-intolerant monkeys. In addition, Moxley and Longmore (12) found that glucose incorporation into PC in isolated, perfused rat lungs was decreased when the lungs of adult diabetic rats were used. These effects could be reversed by insulin treatment prior to perfusion. Studies of insulin action. which depend on isotope incorporation into phospholipids, are, however, complicated by the fact that insulin promotes the uptake of some substrates into cells and may also influence the intracellular pool size of these substrates.

It was the aim of this study to examine the influence of insulin on fetal rat lung maturation in organ culture. Isotope uptake studies were analyzed so as to minimize the influence of insulin on substrate uptake and pool size, and the effect on many phospholipids other than PC was examined. These included the important surfactant components disaturated PC and phosphatidylglycerol $(10.19 .21)$ as well as the phospholipids usually associated with cell membranes, mono- and unsaturated PC. phosphatidylethanolamine. phosphatidylinositol. phosphatidylserine. and sphingomyelin (27). The influence of insulin on enzymes involved with pulmonary phospholipid synthesis was also examined.

\section{MATERIALS AND METHODS}

\section{ORC IAN ( UITTLRE}

The methods used and the morphologic and biochemical characteristics of the culture system have been described in detail previously (5). Timed, 19-day pregnant Sprague-Dawley rats (term is 22 days) were killed by decapitation, and the fetuses were removed under sterile conditions. The lungs were removed and chopped into $1-\mathrm{mm}^{3}$ cubes by means of a Mcllwain tissue chopper. Twenty explants were then placed on a Millipore filter which rested on a stainless steel grid in a $35-\mathrm{mm}$ diameter tissue culture dish. Waymouth's MB $752 / 1$ medium $(5.5 \mathrm{ml})$ containing 100 units penicillin and $100 \mu \mathrm{g}$ streptomycin per $\mathrm{ml}$, but with no added serum, was added to each dish so that the medium just wet the undersurface of the grid. The explants were incubaied at $37^{\circ} \mathrm{C}$ in a humidified atmosphere of $95 \% \mathrm{O}$ and $5 \% \mathrm{CO}$. for $24 \mathrm{hr}$. Control cultures had no insulin added to the culture medium. whereas the experimental cultures contained from 0.01 to 10.0 units of insulin (Regular Iletin: Eli Lilly \& Co. Indianapolis, IN) per $\mathrm{ml}$ or $10^{\text {ti }}$ $M$ dexamethasone phosphate (Decadron: Merck. Sharp and Dohme Inc, West Point, PA). 


\section{BIOC'HEMICAL ANALYSIS}

After $24 \mathrm{hr}$ in culture, the nutrient medium was aspirated and replaced with $5 \mathrm{ml}$ fresh $\mathrm{MB} 752 / 1$ medium containing either 1.25 $\mu \mathrm{Ci}\left[\right.$ methyl- $\left.{ }^{3} \mathrm{H}\right]$ choline chloride $(2.5 \mathrm{Ci} / \mathrm{mol})$ or $35 \mu \mathrm{Ci}\left[{ }^{3} \mathrm{H}\right]$ acetate $(6.4 \mathrm{Ci} / \mathrm{mmol})$, and the incubation was then continued for another $4 \mathrm{hr}$. At the end of the incubation, the explants were washed with ice-cold $0.9 \% \mathrm{NaCl}$ solution and then sonicated in $2 \mathrm{ml} 0.9 \% \mathrm{NaCl}$ solution prior to lipid analysis and protein determination. Lipid was extracted from the sonicate in chloroform and methanol by the method of Bligh and Dyer (1). Phospholipids were identified by thin-layer chromatography on silica gel (LQD plates; Quantum Industries, Fairfield, NJ) after the lipid extract had been divided into three aliquots. The first aliquot was analyzed in a solvent system containing chloroform:methanol:acetic acid: $\mathrm{H}_{2} \mathrm{O}$ (50:35:4: $2, \mathrm{v} / \mathrm{v})$. This system separates lysophosphatidylcholine, sphingomyelin, PC, and phosphatidylinositol plus phosphatidylserine (21). The second aliquot was analyzed in tetrahydrofuran:methylal:methanol:2M NH${ }_{4} \mathrm{OH}$ (50:40:10:5.5, v/v). This system effectively separates phosphatidylethanolamine, cardiolipin, and phosphatidylglycerol (21). The third aliquot was used to isolate disaturated PC by a modification of the method of Mason et al. (11) as follows. PC was isolated by thin-layer chromatography and eluted from the gel in chloroform:methanol:formic acid:water (97: $97: 2: 4, v / v)$. The dried lipid was reacted with osmium tetroxide as described by Mason et al., spotted on a thin-layer chromatography plate, and analyzed in chloroform:methanol:7 $\mathrm{M} \mathrm{NH}_{4} \mathrm{OH}(80: 28$ : $6, v / v)$. It was found that this solvent mixture allowed for complete separation of the disaturated species from the osmium reacted unsaturated species. Total PC 91.1 $\pm 3.4 \%$ (mean \pm S.D.) was recovered by this technique. After visualization by exposure to iodine vapor, the phospholipid-containing spots were scraped off the plates into scintillation vials, and the radioactivity was determined in $0.5 \mathrm{ml} \mathrm{H} \mathrm{H}_{2} \mathrm{O}$ and $14.5 \mathrm{ml}$ Aquasol (New England Nuclear, Boston, MA).

Protein content was determined by the method of Lowry et al. (8), glycogen content was determined by an enzymatic method described previously (9), and DNA was determined by a fluorometric assay, based on binding to mithramycin (Mithracin: Pfizer Laboratories, New York, NY) (7). Standards for these determinations were bovine serum albumin, rabbit muscle glycogen, and calf thymus DNA, respectively. Explants which were used for glycogen analysis were rapidly frozen in test tubes in a solid $\mathrm{CO}_{2}$ and ethanol bath and stored at $-70^{\circ} \mathrm{C}$ until examined.

Glucose oxidation was determined by measuring the rate of oxidation of $\left[\mathrm{U}^{-14} \mathrm{C}\right]$ glucose to ${ }^{14} \mathrm{CO}$.2 as described previously $(5)$.

\section{ENZYME: ASSAYS}

Explants to be examined for enzyme activity were sonicated in chilled $0.33 \mathrm{M}$ sucrose:0.01 M Tris $\mathrm{HCl}: 0.001 \mathrm{M}$ EDTA ( $\mathrm{pH} 7.4$ ). All enzyme assays were performed in the cell-free homogenate except for cholinephosphate cytidylyltransferase which was assayed in the $105.000 \times g$ supernatant fraction. The activities of phosphatidate phosphatase (EC 3.1.3.4), choline kinase (EC 2.7.1.32), cholinephosphate cytidylyltransferase (EC 2.7.7.15). cholinephosphotransferase (F.C 2.7.8.2). 1-acylglycerophosphate acyltransferase (EC 2.3.1.51), and lysolecithin acyltransferase (EC 2.3.1.23) were determined by methods described previously $(6,22$. 23).

\section{MORPHOLOGIC ANALYSIS}

Explants were prepared for light and electron microscopy as described previously (5). Morphologic changes were quantitated with the electron microscopic preparations. Type II cells were identified by the presence of lamellar bodies in the cytoplasm and counted. The number of lamellar bodies in the lining cells contiguous with the alveoli was also determined. Data were expressed as the number of lamellar bodies or type II cells per 10 alveolar lining cells. Lamellar bodies were classified as "early" if they consisted mainly of a central homogeneous core and had relatively few lamellae. "Late" lamellar bodies were those that consisted almost entirely of concentric or laminated lamellar structures.

\section{STATISTICAL. ANAI.YSIS}

In all experiments, except the glycogen dose-response study, the lungs of fetuses from 4 litters were pooled, and this same pool of lungs was used for both the control and experimental groups. Statistical analysis was by $t$ test for dependent variables. In the dose-response study, littermates were not always compared, and statistical significance was therefore evaluated by $t$ test for independent variables.

\section{(HEMICALS}

Radiochemicals were purchased from New England Nuclear. Boston MA. Phospholipid standards were obtained from Serdary Research Laboratories, London, Ontario, Canada. All other biochemicals were purchased from Sigma Chemical Co., St. Louis. $\mathrm{MO}$

\section{RESULTS}

\section{('ARBOHYDRATE METABOI.ISM}

Inasmuch as it was possible that insulin would have an inhibitory effect on some of the parameters to be studied. we selected the dose of insulin used in this project on the basis of optimal stimulation of glycogen synthesis. Choosing the dose on the basis of a maximal inhibitory effect would have increased the chance of merely demonstrating a nonspecific toxic effect of the insulin preparation. As is shown in Table 1 , an increase in glycogen content was noted with doses ranging from 0.01 to 1.0 units insulin per ml. The most consistent (and only statistically significant) increase was observed when $1.0 \mathrm{unit} / \mathrm{ml}$ was used, and this dose was used in all further studies. A decrease in glycogen content occurred with 10 units $/ \mathrm{ml}$, and this was presumably due to a toxic effect.

Although 1 unit $/ \mathrm{ml}$ is a relatively high dose of insulin, it is consistent with that used by Schwartz et al. (24) and Eisen et al. (3) who studied glycogen synthesis in fetal liver explants. Hormones reach the cells of the tissue block in organ culture experiments by diffusion through a $1-\mathrm{mm}$ thick mass of tissue, and this requirement for relatively high doses of hormonal or other agents is a commonly observed phenomenon. It is of interest that the insulin concentration used in this study is almost exactly the same as that in Trowell's T8 medium, a culture medium that was designed specifically for use in organ culture (5).

The oxidation of glucose to $\mathrm{CO}_{2}$ was determined as a measure of the overall viability of the insulin treated explants (Table 2). Exposure to $1 \mathrm{unit} / \mathrm{ml}$ of insulin for $24 \mathrm{hr}$ resulted in a $55 \%$ increase in the rate of glucose oxidation when compared to control cultures. This increase was statistically significant. There was no change in the protein:DNA ratio with insulin treatment.

\begin{tabular}{|c|c|c|c|}
\hline $\begin{array}{l}\text { Insulin concentration } \\
\text { (units } / \mathrm{ml} \text { ) }\end{array}$ & $n^{2}$ & $\begin{array}{l}\text { (ilycogen content } \\
(\mu \mathrm{g} / \mathrm{mg} \text { protein) }\end{array}$ & $P$ \\
\hline 0 & 5 & $151 \pm 8^{3}$ & \\
\hline 0.01 & 3 & $170 \pm 13$ & $\mathrm{NS}^{4}$ \\
\hline 0.10 & 4 & $187 \pm 20$ & NS \\
\hline 1.0 & 5 & $184 \pm 10$ & $<0.05$ \\
\hline 10.0 & 3 & $96 \pm 3$ & $<0.005$ \\
\hline
\end{tabular}

'Explants of 19-day fetal rat lung were cultured for $24 \mathrm{hr}$ as described in the text. Statistical significance was determined by $t$ test for independent variables.

$n$. number of experiments.

${ }^{1}$ Mean \pm S.L:

${ }^{4}$ NS, no statistically significant difference from control value. 


\section{MORPHOLOC;Y}

We have previously shown that explants of fetal rat lung continue both morphologic and biochemical maturation in organ culture in the absence of added serum or hormones (5). As is shown in Table 3, exposure to insulin resulted in a small decrease in the number of early lamellar bodies and a marked decrease in the number of late lamellar bodies when compared to the control cultures. There was also a significant reduction in the number of

Table 2. The influence of insulin on fetal lung protein: DNA ratio

\begin{tabular}{|c|c|c|c|}
\hline & Control & Insulin & $P$ \\
\hline $\begin{array}{l}\text { Protein:DNA ratio } \\
(\mu \mathrm{g} \text { protein: } \mu \mathrm{g} \text { DNA) }\end{array}$ & $7.04 \pm 0.23^{2}$ & $7.44 \pm 0.35$ & $\mathrm{NS}^{3}$ \\
\hline $\begin{array}{l}\text { Flucose oxidation to } \mathrm{CO}_{2} \\
\text { (nmoles } / \mathrm{hr} / \mathrm{mg} \text { protein) }\end{array}$ & $9.12 \pm 1.2$ & $14.2 \pm 1.8$ & $<0.005$ \\
\hline
\end{tabular}

' Insulin-treated cultures were exposed to 1 unit insulin per $\mathrm{ml}$ for 24 hr. Statistical significance was determined by $t$ test for dependent variables. Mean \pm S.E. of 5 experiments.

NS, not significant.

Table 3. The influence of insulin on fetal lung morphology ${ }^{1}$

\begin{tabular}{lrrr}
$\begin{array}{l}\text { Morphologic feature (per } \\
\text { lo alveolar lining cells) }\end{array}$ & Control & Insulin-treated & $P$ \\
Early lamellar bodies & $3.7 \pm 0.9^{\prime 2}$ & $2.2 \pm 0.8$ & $\mathrm{NS}^{3}$ \\
Late lamellar bodies & $5.7 \pm 1.6$ & $1.0 \pm 0.4$ & $<0.05$ \\
Type ll cells & $5.2 \pm 0.7$ & $2.7 \pm 0.6$ & $<0.05$ \\
"early lamellar bodies & $40.9 \pm 6.2$ & $69.2 \pm 10.4$ & $\mathrm{NS}$ \\
\hline
\end{tabular}

'Insulin-treated cultures were exposed to 1 unit insulin per $\mathrm{ml}$ for 24 hr. Statistical significance was determined by $t$ test for dependent variables.

${ }^{2}$ Mean \pm S.E. of 6 experiments.

'NS. not significant.

Table 4. The influence of insulin on choline incorporation into phospholipid in fetal lung ${ }^{1}$

\begin{tabular}{lccc}
\multicolumn{1}{c}{ Phospholipid } & Control & Insulin & $P$ \\
\hline $\begin{array}{l}\text { Phosphatidylcholine } \\
\text { Disaturated phosphatidyl- } \\
\text { choline }\end{array}$ & $619.0 \pm 61.5^{2}$ & $575.3 \pm 51.5$ & $\mathrm{NS}^{4}$ \\
$\begin{array}{l}\text { Sphingomyelin } \\
\text { S }\end{array}$ & $14.6 \pm 1.7$ & $13.1 \pm 1.9$ & $<0.025$
\end{tabular}

' Data are expressed as pmoles choline incorporated into phospholipid per hr per mg protein. Culture conditions and statistical analysis were as described in Table 2

Mean \pm S.E. of 3 to 5 experiments

"NS, not significant. type II cells present in the insulin treated explants. Nineteen-day fetal rat lung contains virtually no lamellar bodies or type II cells, so some maturation had occurred in the insulin-treated explants, but less so than in the controls. In addition, the majority of lamellar bodies present in the treated explants were early forms, whereas the reverse held true in the controls. These findings suggest that direct exposure to insulin delays the morphologic development of fetal rat lung in vitro.

\section{ISOTOPE INCORPORATION INTO PHOSPHOLIPID}

Insulin treatment had no effect on the rate of choline incorporation into total PC or disaturated PC (Table 4). (There was a small decrease in the rate of incorporation into sphingomyelin which was statistically, but probably not biologically, significant.) The influence of insulin and dexamethasone combined was examined in 2 experiments. Dexamethasone treatment increased the rate of choline incorporation into $\mathrm{PC}$, but addition of insulin and dexamethasone to the medium did not abolish the dexamethasone effect. The results obtained (in pmoles choline incorporated into PC per hr per mg protein) were: control, $628 \pm 56$; insulin, 600 \pm 22 ; dexamethasone, $805 \pm 3$; insulin + dexamethasone. $825 \pm$ 58 .

The incorporation of acetate into a number of phospholipids was also studied after exposure to insulin, dexamethasone, and insulin together with dexamethasone (Table 5). To avoid problems related to the effect of insulin on the rate of acetate uptake or acetate pool size, the data were expressed as the percentage of total phospholipid radioactivity measured in each phospholipid fraction. Exposure to insulin resulted in a significant decrease in the percentage of phospholipid radioactivity in the total PC and disaturated PC fractions. Dexamethasone treatment produced the opposite effect, and a combination of insulin and dexamethasone resulted in reversal of the dexamethasone effect. The decreased percentage of radioactivity in the $P C$ fraction after insulin treatment was entirely due to a decrease in disaturated PC because no change was seen in the unsaturated phosphatidylcholines (i.e., the osmium reacted mono- and diunsaturated $\mathrm{PC}$ ). The increased radioactivity in PC which occurred after dexamethasone treatment was also due to an increase in the disaturated PC fraction because the percentage of radioactivity in unsaturated PC actually decreased slightly. The percentage of radioactivity present in each fraction was very consistent from experiment to experiment (as is evidenced by the small standard errors) and thus fairly small changes in the pattern of distribution of radioactivity were highly statistically significant.

Although there was no effect on unsaturated PC, insulin and dexamethasone treatment did result in opposite effects on the synthesis of the other phospholipids which are predominantly components of cell membranes, i.e., phosphatidylethanolamine, phosphatidylserine, phosphatidylinositol, and sphingomyelin. In

Table 5. The influence of insulin and dexamethasone on acetate incorporation into phospholipid in fetal lung

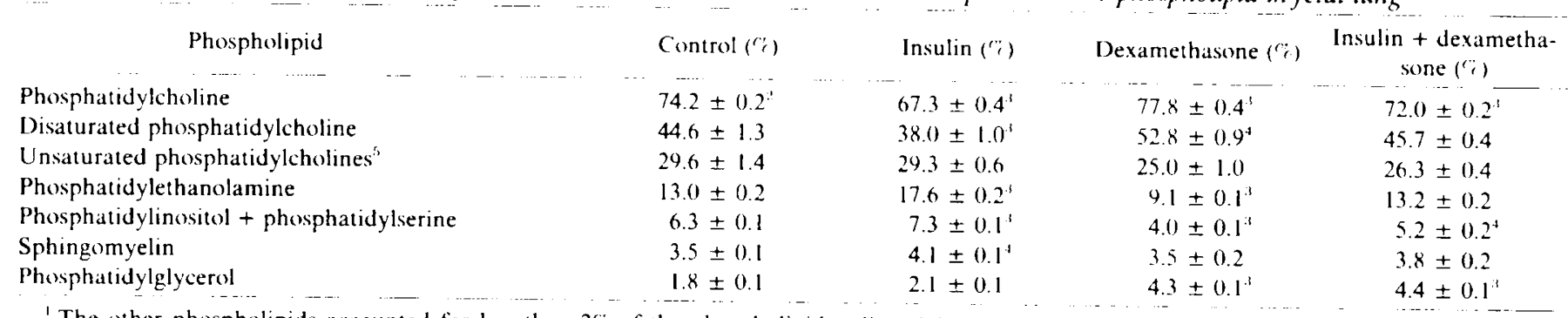

'The other phospholipids accounted for less than $2 \%$ of the phospholipid radioactivity. Nineteen-day fetal lung was cultured for 24 hr. Insulintreated cultures were exposed to 1 unit insulin per $\mathrm{ml}$, and dexamethasone-treated cultures were exposed to 10 " $\mathrm{M}$ dexamethasone. Data are expressed as the percentage of total phospholipid radioactivity derived from ["H]acetate in each phospholipid fraction.

Mean \pm S.E. of 5 experiments.

${ }^{3}$ Statistically significant difference from control value, $P<0 .(0) 1$

${ }^{4} P<0.01$.

"Unsaturated phosphatidylcholines" refer to the osmium-reacted mono- and diunsaturated phosphatidylcholine species. 
the case of these phospholipids, however, insulin increased the percentage of radioactivity in each fraction. whereas dexamethasone generally decreased it. This effect was most obvious with phosphatidylethanolamine. In addition, insulin tended to negate the dexamethasone effect when the two hormones were added logether.

The results obtained with phosphatidylglycerol. an important surfactant phospholipid, did not conform to this pattern. however. Both insulin and dexamethasone increased the percentage of radioactivity in this phospholipid. This effect was particularly noteworthy in the case of dexamethasone.

To rule out the possibility that the effects seen in the insulin treated cultures could be due to some component of the insulin preparation other than the insulin itself, the acetate incorporation studies were repeated using insulin which had been heated to $1000^{\circ} \mathrm{C}$ for $30 \mathrm{~min}$. The preservatives are not destroyed by this procedure. The distribution of radioactivity observed after incubation with this heated preparation was the same as in the control cultures.

Table 6 shows the actual rate of acetate incorporation into the various phospholipids after insulin treatment. The rate of incorporation into total phospholipid was slightly increased, as was that into phosphatidylethanolamine. phosphatidylinositol plus phosphatidylserine. sphingomyelin. and phosphatidylglycerol. Incorporation into disaturated PC was decreased. whereas that into unsaturated PC was unchanged.

When the activity of enzymes involved with phospholipid synthesis was examined after insulin treatment. the results were somewhat surprising. As is shown in Table 7. exposure to insulin

Table 6. The influence of insulin on acetate incorporation into phospholipid in fetal lung

\begin{tabular}{|c|c|c|c|}
\hline Phospholipid & Control & Insulin & $P$ \\
\hline Total phospholipid & $731.2 \pm 23.4$ & $781.6 \pm 31.3$ & $<0.05$ \\
\hline Total phosphatidylcholine & $542.7 \pm 18.4$ & $526.3 \pm 21.3$ & $\mathrm{NS}^{s}$ \\
\hline $\begin{array}{l}\text { Disaturated phosphatidyl- } \\
\text { choline }\end{array}$ & $325.8 \pm 13.5$ & $266.7 \pm 11.9$ & $<0.05$ \\
\hline $\begin{array}{l}\text { Unsaturated phosphatidyl- } \\
\text { cholines }\end{array}$ & $216.9 \pm 12.8$ & $228.4 \pm 12.5$ & NS \\
\hline Phosphatidylethanolanine & $94.6 \pm 2.5$ & $137.5 \pm 5.9$ & $<0.001$ \\
\hline $\begin{array}{l}\text { Phosphatidylinositol + } \\
\text { phosphatidylserine }\end{array}$ & $45.7 \pm 1.5$ & $57.1 \pm 2.4$ & $<0.605$ \\
\hline Sphingomyelin & $25.3 \pm 1.3$ & $31.7 \pm 1.5$ & $<0 .(0) 1$ \\
\hline Phosphatidylglycerol & $13.3 \pm 0.9$ & $16.8 \pm 1.5$ & $<0.025$ \\
\hline
\end{tabular}

The other phospholipids accounted for less than $2 \%$ of the phospholipid radioactivity. Data are expressed as $\mathrm{dpm}$ ['H]acetate incorporated into phospholipid per $\mathrm{hr}$ per $\mathrm{mg}$ protein $\left(\times 10^{-}\right)$. Culture conditions and statistical analysis were as described in Table 2

Mean \pm S.L. of 5 experiments.

NS. not significant

Table 7. The influence of insulin on the activity of enzimes involved with phospholipid sinthesis ${ }^{\prime}$

$$
\text { Insme }
$$

1-Acylglycerophosphate acyltransferase

Phosphatidate phosphatase

Choline kinase

('holinephosphate cytidylyltransferase

Cholinephosphotransferase

Lysolecithin acyltransferase

$\begin{array}{cccc}n & \text { Control } & \text { Insulin } & \frac{P}{\mathrm{NS}^{3}} \\ 8 & 3.3 \pm 0.2^{2} & 3.7 \pm 0.2 & \\ & & & \mathrm{NS} \\ 4 & 5.6 \pm 0.5 & 5.5 \pm 0.4 & \mathrm{NS} \\ 4 & 530 \pm 27 & 672 \pm 58 & <0.025 \\ 5 & 623 \pm 35 & 534 \pm 80 & \mathrm{NS} \\ & & & \\ 3 & 560 \pm 30 & 520 \pm 43 & \mathrm{NS} \\ 8 & 4.1 \pm 0.1 & 4.8 \pm 0.2 & <0.01\end{array}$

'Enzyme activities are expressed as pmoles/min/mg protein. except for phosphatidate phosphatase and the acyltransferases which are expressed as nmoles $/ \mathrm{min} / \mathrm{mg}$ protein. Culture conditions were as described in Table 2.

Mean $\pm S . E$

${ }^{1}$ NS, not significant. resulted in a small stimulation of choline kinase and lysolecithin acyltransferase activity and no change in the other activities examined. There was a 15\% decrease in the activity of cholinephosphate cytidylyltransferase, but this change was not significant.

\section{DISC USSION}

There is considerable controversy regarding the role of insulin in fetal lung maturation. Although the finding of Robert $e t a l$. (18) that infants of diabetic mothers have a 5.6-fold greater incidence of RDS than do age- and weight-matched controls would seem to indicate that fetal hyperinsulinemia delays lung maturation. experimental studies have not always borne this out.

In favor of this theory are the studies of Smith et al. (25). Sosenko et al. (26) and Rhoades (17), as well as our own data. Smith et al. have reported that insulin alone has a slight stimulatory effect on the incorporation of choline into $\mathrm{PC}$ in monolayer cultures of mixed fetal rabbit lung cells. Cortisol also stimulates the incorporation of choline into PC in this system, but if insulin is added together with cortisol, the stimulatory effect of cortisol is abolished. They have therefore postulated that insulin antagonizes the physiological corticosteroid-induced stimulation of lung PC synthesis in the developing fetus. In a preliminary report. Sosenko 't al. (26) found that decreased alveolar lavage surfactant (as measured on a surface balance) was obtained from the fetuses of alloxan-diabetic rabbits. The data of Rhoades (17) tend to support this observation in that the lungs of newborn rats born to streptozotocin-treated mothers contained a decreased percentage of disaturated PC. Total phospholipid and PC content was actually increased, however. The data in this study cannot be compared directly to those obtained from fetal animals in diabetic pregnancies because the fetal animals are both hyperglycemic and hyperinsulinemic, whereas the newborns are hypoglycemic and hyperinsulinemic. In addition the lung and body weights of the newborn rats were decreased in this study. suggesting that the animals may have been stressed.

In contrast to these studies. Epstein et al. (4), working with glucose-intolerant rhesus monkeys, found an increase in the amniotic fluid lecithin/sphingomyelin ratio and an increased rate of choline incorporation into $\mathrm{PC}$ in slices prepared from the lungs of the fetuses, but no change in the whole lung PC content. This finding of an insulin-induced increase rather than decrease in the rate of precursor incorporation into $\mathrm{PC}$ is consistent with the data of Moxley and Longmore (12). They found that glucose incorporation into $P C$ and phosphatidylglycerol in the isolated perfused rat lung was decreased in lungs obtained from adult diabetic rats and that this effect could be reversed by insulin treatment of the animals prior to removing the lungs. Insulin promotes glucose uptake by cells, and the decreased rate of glucose incorporation reported by Moxley and Longmore could be due to this effect only. In addition, it is difficult to relate the acute effect of a hormone on a metabolic process in the adult to a longer term effect on organ development in the fetus. In another study of adult diabetic rats. Plopper and Morishige (16) reported that the type II cells showed dilation of the granular endoplasmic reticulum, but no decrease in the number of lamellar bodies. This change was reversible with insulin.

We have attempted to avoid some of the isotope uptake problems in this study of the direct effect of insulin on fetal lung morphology and biochemistry in vitro. Although. as is common in organ culture studies, a high dose of insulin was required, our data indicate that insulin stimulates glycogen accumulation and glucose oxidation by fetal rat lung and simultaneously delays lung maturation as evidenced by a decrease in the number of lamellar bodies and type II cells and the percentage of radioactivity derived from $\left[{ }^{3} \mathrm{H}\right]$ acetate in the disaturated PC fraction. Type II cells did develop in the insulin-treated cultures, but in smaller numbers than in the controls.

The rate of choline incorporation into disaturated PC was not decreased by exposure to insulin and, in contrast to the cell culture data of Smith et al. (25), we did not find any antagonism between 
insulin and corticosteroid with regard to the rate of choline incorporation. It is possible that insulin may be increasing the rate of uptake of choline by the lung cells or decreasing the intracellular choline pool size, thereby negating any changes in choline incorporation that would occur as a result of a lower rate of PC synthesis. The stimulation of choline kinase, the first step in the incorporation of choline into PC, may also play a role in this effect of insulin on choline incorporation. It is of interest that none of the studies published thus far have shown that insulin alone decreases the rate of choline incorporation into PC $(4,25)$.

To study the influence of insulin on other phospholipids, we also examined the influence of insulin on acetate incorporation into phospholipid. The data were expressed both as the absolute rate of incorporation of acetate into phospholipid and as the percentage of radioactivity derived from acetate in each phospholipid fraction. The latter calculation reduces, but does not eliminate, uptake and pool size problems because it is based on the assumption that the lung acetate pools are influenced to the same extent by insulin or that all the acetate incorporated into phospholipids is derived from the same intracellular pool. Essentially, these studies showed that insulin and dexamethasone have antagonistic effects with regard to acetate incorporation into phospholipid. Insulin treatment resulted in a decrease in the percentage of phospholipid radioactivity in the major surfactant phospholipid. disaturated PC: and increased radioactivity in those phospholipids which are important cell membrane constituents, but minor components of surfactant. Dexamethasone treatment had the opposite effect and addition of insulin and dexamethasone together diminished the dexamethasone effect. The inhibitory effect of insulin was specific to disaturated PC and did not extend to the other important surfactant phospholipid. phosphatidylglycerol. When the data were expressed as the absolute rate of acetate incorporation into phospholipid, it was found that insulin decreased acetate incorporation into disaturated PC, had no effect on unsaturated $\mathrm{PC}$ and stimulated incorporation into all the other phospholipids.

It is difficult to explain the effects of insulin action on the basis of the small changes in enzyme activity observed, i.e., the stimulation of choline kinase and lysolecithin acyltransferase and the tendency towards decreased cholinephosphate cytidylylt ransferase activity. The role of choline kinase in the regulation of lung PC synthesis is unclear, but there is increasing evidence that the cytidylyltransferase is an important factor in this process. This is based on the observation that both corticosteroids and estrogen increase the activity of this enzyme in fetal lung (20). Rhoades (17) has reported that the activities of choline kinase, cholinephosphate cytidylyltransferase, and cholinephosphotransferase are increased in the newborn offspring of glucose intolerant rats. However. as discussed previously, data in that report indicate that the animals may have been stressed, and it is therefore difficult to interpret those results. Our finding of a small increase in the activity of lysolecithin acyltransferase is inconsistent with the decreased radioactivity in disaturated PC reported here. Further studies in this area are required, and the activities of other enzymes involved with the synthesis of disaturated PC specifically should be examined.

Insulin is known to promote growth in the developing fetus (15). The observations reported here support the hypothesis that insulin promotes lung growth, as measured by "membrane phospholipid" synthesis, at the expense of lung differentiation, as measured by morphologic parameters and disaturated PC synthesis. This statement has to be qualified by the fact that these observations were made entirely in an in vitro system. Although organ culture is in many ways the most "physiologic" of the culture systems, it would be incorrect to directly extrapolate from these data to the in vivo situation.

Despite this reservation. the data presented here support the concept that insulin plays a role in the pathogenesis of the increased incidence of RDS which occurs in prematurely delivered infants of diabetic mothers. These findings also lend theoretical support to the current attempts by some obstetricians (2) to more rigorously control maternal blood glucose levels in diabetic pregnancies to reduce the glucose load to the fetus and the resulting fetal hyperinsulinemia.

\section{REFERENCES AND NOTES}

I. Bligh. E. (i.. and Dyer, W. J.: A rapid method of total lipid extraction and purification. Can. J. Biochem. Physiol.. 37: 911 (1959).

2. Coustan, D. R. and Lewis. S. B.: Insulin therapy for gestational diahetes. Obstet. (iynecol. $51: 306(1978)$.

3. Eisen. H. J.. Goldfine. I. D. and Glinsmann. W. H.: Regulation of hepatic glycogen synthesis during fetal development: role of hydrocortisone, insulin and insulin receptors. Proc. Natl. Acad. Sci. U. S. A.. 7i) 3454 (1973).

4. Epstein. M. F. Farrell, P. M. and (hes. R. A. Fetal lung lecithin metabolism in the glucose-intolerant rhesus monkey pregnancy. Pediatrics. $5^{5}: 722$ (1976).

5. Ciross. I.. Smith. (j. J. W.. Maniscalco. W. M.. (zajka. M. R.. Wilson. ('. M... and Rooney. S. A.: An organ culture model for study of biochemical development of fetal rat lung. J. Appl. Physiol., $45: 355$ (1978).

6. Ciross. 1., Wilson, (. M.. Ingleson. L.. D.. Brehier, A.. and Rooney, S. A.: The influence of hormones on the biochemical development of fetal rat lung in organ culture. I. Estrogen. Biochim. Biophys. Acta, 575: 375 (1974).

7. Hill. B. T.. and Whatley, S.: A simple rapid microassay for IDNA. FEBS Lett. 56: $20(1975)$

x. L.owry, O. H., Rosebrough. N. J.. Farr, A. L... and Randall. R. J.: Protein measurements with the Folin phenol reagent. J. Biol. (hem. 103: 26.5 (1951)

9. Maniscalco. W. M.. Wilson. (. M.. Gross. I., Gobran. L... Ronnev. S. A. and Warshaw. J. B.: Development of glycogen and phospholipid metaholism in fetal and newhorn rat lung. Biochim. Biophys. Acta, 530 : 333 (1978).

10. Mason. R. J.: Disaturated lecithin concentration of rabbit tiscues. Am. Rev. Respir. Dis., 107 : 678 (1973).

11. Mason. R. J., Nellenbogen. J., and Clements. J. A.: Isolation of disaturated phosphatidylcholine and osmium tetroxide. J. Lipid Res.. $/ ?: 281$ (1976).

12. Moxley, M. A.. and Longmore. W. J.: Effect of experimental diahetes and insulin
on lipid metabolism in the isolated pertised rat lung Biochim Biophys Acta. on lipid metabolism in the isolated pertused rat lung. Biochim. Biophys. Acla.
f.S.: 218 (1977).

13. Obenshain, S. S.. Adam. P. A. J.. King. K. (.. Teramo, K.. Raivio. K. O.. Raiha, N., and Schwartz, R.: Human fetal insulin response to sustained maternal hyperglycemia. N. Engl. J. Med.. 2\&3:566(1970).

14. Pederson, J.: Weight and length at birth of infants of diabetic mothers. Acta Endocrinol.. 16: 330 (1954).

15. Picon. L.: Fffect of insulin on growth and biochemical composition of the rat fetus. Endocrinology, $81:$ 1419 (1967).

16. Plopper. ( . G... and Morishige, W. K.: Alterations in granular (type II) pneumocyte ultrastructure by streptorotocin-induced diabetes in the rat. Lab. Invest.. 38: 143 (1978)

17. Rhoades. R. A.: Influence of maternal diabetes on lipid metabolism in neonatal rat lung. Biochim. Biophys. Acta, $5 \%$ ?: $132(1979)$.

18. Robert. M. F. Neff, R. K.. Hubbell. J. P.. Taeusch. H. W.. and Avery. M. E. Association hetween maternal diabetes and the respiratury distrew ivindrome

in the newhorn. N. Engl. J. Med.. 244: $357(1976)$.
19. Rooney. S. A.. Canavan. P. M.. and Motoyama. F. K.: The identification of phosphatidylglycerol in the rat. rabbit. monkey and human lung. Biochim. Biophys. Acta, 360: 56 (1974).

20. Rooney. S. A.. and (iross. I.: Stimulation of fetal lung cholinephosphate cytidylyltransferase activity by glucocorticoids and estrogen in the rabbit in viro and the rat in vitro. Am. Rev. Respir. Dis., 119: 354 (1974).

21. Rooney. S. A.. Nardone. 1. L.. Shapiro, D. L.. Motoyama. E. K., and ciohran. L.: The phospholipids of rabbit type II alveolar epithelial cells: comparison with lung lavage, lung tissue, alveolar macrophages, and a human alveolar tumor cell line. Lipids, 12: $43 \times$ (1977).

22. Rooney. S. A. and Wai-Lee. T. S.: ( holinephosphotransferase from rabhit lung microsomes. An improved assay and specificity lowards exogenous dacylglyeerols. l.ung. 154: 201 (1977).

23. Rooney. S. A.. Wai-1.ee. T. S.. Cobran. 1... and Motoyama. E. K.: Phospholipid content. composition and biosynthesis during fetal lung development in the rabbit. Biochim. Biophys. Acta, 431: 447 (1976).

24. Schwark. A. L.. Raiha. N. C. R.. and Rall. T.: Hormonal regulation of glycogen metabolism in human fetal liver I. Normal development and effects of dibutyry cyclic AMP. glucagon and insulin in liver explants. Diabetes. 24: 11011 (1975)

25. Smith. B. T.. Giroud. C. J. P.. Robert. M.. and Avery. M. E.: Insulin antagonism of cortisol action and lecithin synthesis by cultured fetal lung cells. J. Pediatr. S?: $953(1975)$

26. Sosenko, I. R. S.. Lawson. E. E.. Demottaz. V.. and Frantz. 1. D.: Delayed lung maturation in fetus of alloxan diabetic rabbits. Pediatr. Res.. 12:569 (1978).

27. White. D. A.: The phospholipid composition of mammalian tissues. In: (j. B Ansell. R. M. C. Dawson. J. N. Hawthorne: Form and function of phospholipids. p. 441 (Elsevier. Amsterdam. 1973).

28. The authors thank Donna Light for excellent technical assistance. Debra (amputaro for heip with the manuscript, and Joseph B. Warshaw. M.D., for numerous useful discussions regarding this project.

29. Requests for reprints should be addressed to: Dr. Ian (iross. Department of Pediatrics, Yale University School of Medicine, 333 (edar Street. New Haven.
(T 06510 (USA).

30 This research was supported by USPHS grant HL-19752 and HD-11018

31. Received for publication April 19. 1979.

32. Accepted for publication September 14. 1979 